\title{
Tzolkin: monitor mesoamericano de sequía
}

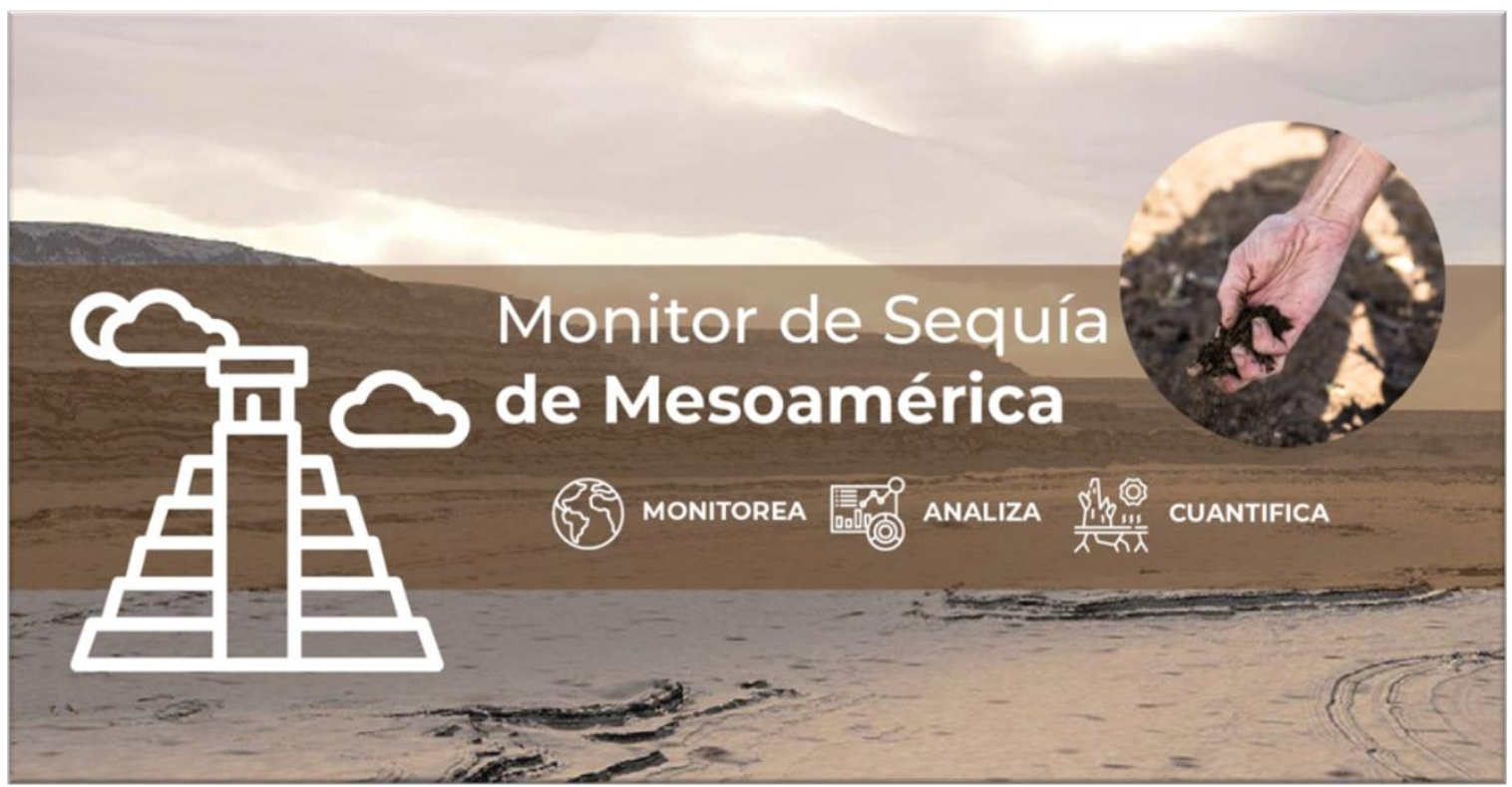

Trabajo de cooperación interinstitucional e internacional para el monitoreo de sequías en Mesoamérica

- Herramienta de acceso libre y abierto, disponible en: http://galileo.imta.mx/Sequias

El Instituto Mexicano de Tecnología del Agua, en conjunto con la Agencia Mexicana de Cooperación Internacional para el Desarrollo y la Organización de las Naciones Unidas para la Alimentación y la Agricultura, ha desarrollado Tzolkin, un monitor de sequías para la región de Mesoamérica.

Tzolkin es una herramienta de acceso libre y abierto; es decir, toda la información está disponible al público de manera gratuita, desde la información de sequía que se despliega en una página web (1) hasta el código fuente que la genera (2). Inclusive la información hidrológica, que sirve de insumo para Tzolkin, a pesar de que es propiedad de un tercero (NASA), es información pública; por lo que el usuario puede reproducir paso a paso la información presentada por este monitor, lo que la hace una herramienta totalmente transparente. 
PERSPECTIVAS IMTA

$N^{\circ} .5,2020$

MEDIO AMBIENTE

Autor: Mauricio Osorio González

DOI: $\underline{\text { doi.org/10.24850/b-imta-perspectivas-2020-05 }}$

Tzolkin es una palabra maya que significa "la cuenta ordenada de los días", que es la versión maya del ciclo sagrado, el cual fue utilizado en la Mesoamérica precolombina, entre otras cosas, para la calendarización del cultivo del maíz.

\section{La sequía en Mesoamérica}

La sequía es un fenómeno que afecta a todo el mundo. Sin embargo, regiones como la mesoamericana son particularmente vulnerables, debido a la importancia de la agricultura de temporal en las economías nacionales y a otros factores socioeconómicos. En Centroamérica, el daño asociado a la sequía ha tendido a ser más frecuente, especialmente en las regiones asociadas al corredor seco (principalmente Guatemala, El Salvador, Nicaragua y Honduras). En este corredor, la sequía es la principal amenaza a la producción de cultivos como el maíz y el frijol, los cuales, además de tener gran importancia cultural y económica, representan la base de la alimentación de la población más pobre (Orgaz, 2019).

La mitad de los pequeños productores de granos básicos que existen en Centroamérica se encuentran en la zona del Corredor Seco (entre el 54 y el 67 \% en función del país). Estas familias viven en zonas con infraestructura y servicios limitados, y apenas cuentan con recursos para hacerle frente al fenómeno. Es por esto que se es necesario desarrollar herramientas que permitan disminuir los riesgos. Mejorar el monitoreo y la caracterización de la sequía contribuye a este propósito (Bonilla-Vargas, 2014).

\section{Definición y caracterización de la sequía}

De acuerdo con la Sociedad Meteorológica Americana, la sequía es un fenómeno climático natural que se manifiesta como un periodo de déficit de agua, cuya duración es suficientemente prolongada como para causar desequilibrios hidrológicos significativos. Sin embargo, existen otras definiciones de sequía que se orientan hacia los distintos impactos de este fenómeno, las cuales se pueden clasificar en cinco principales: sequía meteorológica, sequía agrícola, sequía hidrológica, sequía hidrogeológica y sequía socioeconómica.

Para cada tipo de sequía se han propuesto índices para cuantificar su severidad. Por ejemplo, el Índice Estandarizado de Precipitación (SPI, por sus siglas en inglés) (McKee, 1993) es utilizado para caracterizar la sequía meteorológica. Este tipo de índices consideran una sola variable. Otros índices de este tipo son el Índice Estandarizado de Escurrimiento Superficial (SRI) (Shukla \& Wood,2008) y el Índice Estandarizado de Humedad de Suelo (SSI) (Hao y Aghakouchak, 2013). Posteriormente se comenzó a explorar la posibilidad de incorporar, probabilísticamente, más de una variable para caracterizar la sequía, dando lugar a los índices estandarizados multivariados de sequía (MSDI) (Hao y Aghakouchak, 2014). Estos índices demostraron su utilidad al mostrar las cualidades de cada índice en un solo indicador.

Otro aspecto importante a considerar en la caracterización de la sequía es la calidad y cantidad de datos. Los procesos del ciclo hidrológico se miden generalmente con estaciones climatológicas e hidrométricas; en regiones donde estas son escasas o nulas, no es posible caracterizar la sequía de manera adecuada. Para resolver el problema de la escasez de datos, en las últimas décadas se han desarrollado diversos proyectos en el mundo sobre reanálisis. Estos son productos que asimilan información satelital y observaciones terrestres para reproducir variables climáticas y procesos de la superficie terrestre. 
PERSPECTIVAS IMTA (0)

$N^{\circ} .5,2020$

Autor: Mauricio Osorio González

DOI: doi.org/10.24850/b-imta-perspectivas-2020-05

Tzolkin es una herramienta de consulta en línea que obtiene datos de precipitación, humedad de suelo y escurrimiento de la base de datos MERRA-2 (Modern-Era Retrospective Analysis for Research and Applications versión 2 (MERRA-2; Rienecker, et al., 2011) y calcula los siguientes índices:

- índice estandarizado de precipitación (SPI)

- índice estandarizado de humedad del suelo (SSI)

- índice estandarizado de escurrimiento (SRI)

- índice estandarizado multivariado de precipitación y humedad del suelo (MSDI-PreSMo)

- índice estandarizado multivariado de precipitación y escurrimiento (MSDI-PreRun)

- índice estandarizado multivariado de precipitación, humedad del suelo y escurrimiento (MSDIPresMoRun)

Estos índices pueden visualizarse mediante mapas georreferenciados. Las escalas temporales disponibles son de 1, 3, 6, 9 y 12 meses, lo que ayuda a identificar la proporción de los periodos secos. Además, se pueden realizar consultas dinámicas de series de tiempo de intensidad, magnitud de sequía y porcentaje de área afectada para cada país de Mesoamérica.

El objetivo de Tzolkin es contribuir al desarrollo y la seguridad alimentaria de la región a través de una herramienta robusta y al alcance de todos, que presente información diversa para la caracterización de sequías y que sirva en la toma de decisiones para reducir los riesgos asociados a la sequía.

Referencias

Bonilla-Vargas, A. (2014). Patrones de sequía en Centroamérica (1). Obtenido el 11 de mayo de:

https://www.gwp.org/en/search/?query=Patrones+de+sequ\%C3\%ADa+en+Centroam\%C3\%A9rica\&Ing=es

Hao, Zengchao \& AghaKouchak, Amir. (2013). Multivariate Standardized Drought Index: A parametric multi-index model. Advances in Water Resources. 57. 12-18. 10.1016/j.advwatres.2013.03.009.

McKee, T. B., Doesken, N. J., \& Kleist, J. (1993). The Relationship of Drought Frequency and Duration to Time Scales. Eight Conference on Applied Climatology, January 17-22, Anaheim, California.

Orgaz, C. J. (2019). ¿Qué es el Corredor Seco y por qué está ligado a la pobreza extrema en casi toda Centroamérica? Obtenido el 11 de mayo de: https://www.bbc.com/mundo/noticias-america-latina-48186820

Rienecker, M.M., Suarez, M.J., Gelaro, R., Todling, R., , J.T., Liu, E., Bosilovich, M.G., Schubert, S.D., Takacs, L., Kim, G.K., Bloom, S., Chen, J., Collins, D., Conaty, A., Da Silva, A., Gu, W., Joiner, J., Koster, R.D., Lucchesi, R., Molod, A., Owens, T., Pawson, S.,

Pegion, P.J., Redder, C.R., Reichle, R.H., Robertson, F.R., Ruddick, A.G., Sienkiewicz, M., Woollen, J., 2011. MERRA: NASA's modern-era retrospective analysis for research and applications. Journal of Climate 24, 3624-3648.

Shukla, S., Wood, A.W., 2008. Use of a standardized runoff index for characterizing hydrologic drought. Geophysical Research Letters 35, 1-7.

(1) Disponible en: http://galileo.imta.mx/Sequias

(2) Disponible en: https://github.com/rrealrangel/droughtMoPro 
PERSPECTIVAS IMTA (0)

$N^{\circ} .5,2020$

Autor: Mauricio Osorio González

DOI: doi.org/10.24850/b-imta-perspectivas-2020-05 